\title{
The Measures of Light Performance of Wind Catchers in Hot Climatic Zones
}

\author{
Egal Kkalaf Aljofi
}

\begin{abstract}
The development of contemporary nations and society had been characterized by the abilities and skills of their inhabitants in various sectors. Some of these nations decreased over a period of time and were substituted by others. Yet they remain marks of architecture and historical features that stand out as landmarks. The architectural heritage represents the most common and clear evidence for these nations. Therefore, many civilizations attempt to conserve, explore and develop the essence of its architectural vocabularies. GCC countries have been characterized by architectural style that emerged from its environmental and geographical circumstances. Wind catchers are one such feature. The use of this device had decreased over the years. However, they emerged again in many contemporary buildings but without their functional characteristics.

The purpose of this research is to investigate and explore the natural light characteristics of this device through the investigation of old existing device and explore the effectiveness of its parameters and factors applicability.
\end{abstract}

Index Terms - Light performance, wind catchers, traditional gulf architecture, natural light.

\section{INTRODUCTION}

The architectural heritage represents the most common and clear evidence of nations history. Therefore, many civilizations attempt to conserve, explore and develop the essence of its architectural vocabularies to maintain its values Every contemporary society possesses Architectural features that are witness of their roots and extension of their civilization. The pyramids had been landmark for the Pherohnic period. The dome symbolizes the feature of roman culture. The various types of arches represent the Persian and Andalusian nations. Those features and landmarks might be the result of environmental and /or social needs.

GCC countries specially characterized by architectural styles that have been emerged from their topographical, geographic, and climatic conditions. Some of these architectural features are still exist. Some of these were due to social factors such as the courtyards, which support the climatic and social issues. There were some features such as coral stone walls evolved due to topographical factors. Some others had been used for natural ventilation such as Roshans. Wind catchers also represent a very common feature in these regions [1].

The propriety of GCC nations had a strong influence on the socio-cultural aspects of the people which resulted in a changed life style. Along with it the availability of new contents, materials and technologies led to new building

Manuscript received May 7, 2014; revised July 25, 2014

Egal Kkalaf Aljofi is with the University of Dammam, Saudi Arabia (e-mail: ealjofi@gmail.com). forms which influenced the psychological aspects of human life.

Air conditioning eliminated the need of wind catchers; as the demand for comfort levels could not be achieved with these features. However, a desire emerged in the societies specially those countries along the Arabian Gulf to incorporate wind catchers simply as an ornamental feature without any functional values. The main purpose was to maintain continuity with the past in term of ornamental heritage.

\section{HISTORICAL BACKGROUND}

Wind catchers had been found extensively in hot regions to improve the ventilations levels by utilizing the high winds and to draw it into the living spaces at lower floors. Although, these features had been found in various society of different cultural background, yet the main function remains the same with different names. It had been known as wind catchers in the gulf region. Yet it is more common to be named as "Badjeers in Iran" which means the wind tower in Persian [2].

The wind catcher had been used as early as 1300 B.C. in house of "nib Ammon" house, where the device had multiple openings, one for cool air to damped in, while the other for hot air to escape out [3].

This device had been found with different technical details and forms. Some were simple from light material. Others are small inclined shaded panels on the roof made of wood. Alsehimi and Alsenary house represent the most famous ones with that type of wind catcher in Cairo. Some of the developed and detailed wind catchers had been found in many countries such as Iran, Pakistan, Afghanistan, Iraq, Egypt, and the GCC countries.

Wind catchers concept initially adapted from Iran to the GCC countries at the beginning of the $18^{\text {th }}$ century as the pearl trade flourished in Bahrain [4].

\section{THE ARCHITECTURAL DESCRIPTION}

The wind catcher was considered to be the most important cooling system that had been used in traditional architecture. According to the researchers and scholars, the design of this device in variety of shapes and technical details based on climatic conditions is an indication of wide vision and invention of architecture.

Wind catcher can be defined as the architectural component that usually had been built on the roof to extract the high air pressure into the rooms and the corridors in building interior. It was known in Bahrain as "cashteel", and 
in Imarets as "Barjeel", in Qatar as "badkeer", and in eastern province of Saudi Arabia, in Alhasa as "badjeen". This word had been originally consisting of two

Persian wards; "Bad" which means air, and "keer" which means take or catch [2]. Wind towers are group of vertical ducts surrounded by external four walls forming square shape, and two internal diagonal walls. Sometimes these internal walls could be in other different shapes $(\mathrm{K}, \mathrm{H}, \mathrm{L}, \mathrm{I})$ [5].

The wind tower consists of three parts, Fig. 1. The bottom part is solid and called "the tower base". However, Side windows could be found. The medium part "the tower body" contains three rectangular units or more that ended with ornamentation and little arched shapes through which horizontal wooden pillars. The top part of the tower is called "Alttaj" which means the crown. Its mean function is to define the end of the tower. It might be simple of consist of small ornamentation [6].

The area of the tower base is more than its body to allow for drafting more air into the base and reduce air speed to avoid the penetration of dust; especially in dry regions. The internal surfaces of the

Tower had been plastered to absorb the excessive humidity and allow for air with less humidity [6].

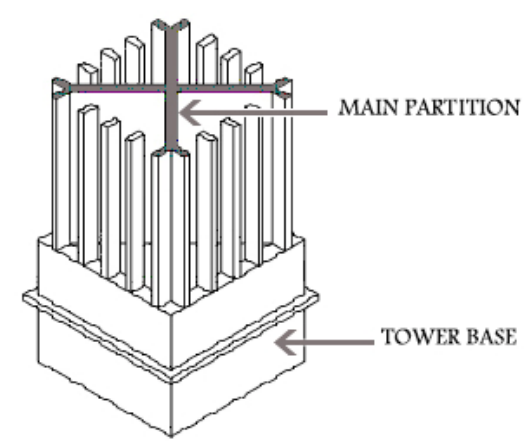

Fig. 1. The main components of the tower.

\section{THE ENVIRONMENTAL CHARACTERISTICS}

The old Islamic cities contain many architectural elements that had been originated as a result of climatic solutions to reduce the harsh high temperature during the summer months. There were simple and innovative solutions to overcome the different climatic conditions. These elements could be analyzed to enable the architect to develop them in modern manner.

The wind towers had been one of these elements that drew the attention of modern designers. Wind towers vary in its typology and characteristics depending on the climatic condition and the wind type. In dry regions, a water jar to increase its humidity. In humid regions, absorbers had been fixed to reduce its humidity level. Moreover, the air in the towers of the Emirates and Bahrain, in particular, receive air from four direction of the tower, where its body located within the internal surfaces of the building to avoid the sun exposure to maintain the cooled air [7]. Since the different parts of the tower meant to improve the human comfort inside the building. Water jars and internal perpendicular surface play an important role in this function [6]. The side openings of the architectural spaces at the bottom of the towers contribute in extracting the hot air and allow for cross ventilation.

The Cooling system of the wind tower depends on either the sensible or evaporative cooling. The first one was based on the reduction of temperature as air passed through the space without the change in the humidity level. The evaporative cooling depends on the reduction of temperature through the increase of water vapor level as dry air pass through water body. These techniques had been used to cool water tanks as in wind towers of Azad city, Iran [7].

The use of wind tower became more essential in densely inhibited areas where closely packed buildings could not get adequate ventilation through windows. Previously, many researchers explored the environmental characteristics of wind towers, which concentrated in understanding the thermal behavior and the improvement of natural ventilation. In Azad city, analytical and laboratory studies intentioned to recognize the thermal performance and utilizing the prevailing winds of the hot air with low humidity. Many mechanical and mathematical studies with the help of software simulation programs had been used [5]. This proved that the type of internal walls of the wind towers positively influenced the human comfort level inside the adjacent architectural spaces to the tower.

\section{A. The Natural Light Characteristics}

The ventilation issues through wind tower had been mostly investigated. Recently, the main environmental function of these towers reduces its importance. This is due to the fact that the human comfort level had been changed with the change of occupants' habits, behaviors, and demands. Moreover, they used mechanical means to cool their buildings. The towers need to be controlled to avoid the dust and insects' penetration. The recent modern wind catchers developed to overcome these problems are not widely known in this region. However, to maintain the use of the tower as a cultural and traditional architectural device became dominant, but not environmentally functional. As the composition of the tower indicates the possibilities of its utilization as a light giver, it is practical to encourage its use as a lighting device.

\section{THE MODERN WIND TOWERS}

As a result of the use of modern building techniques; the traditional architecture has been influenced negatively; and they slowly disappeared. However, due to the nature of human being to explore their roots, some architectural solutions tried to emerge between the contemporary architecture and the traditional architectural values. The reaction of the architects for the use of traditional architectural features varies from the way the western architects did. The local and eastern architects tried to use these components as pure forms in the modern vocabs [3]. Some of those architects who contributed in the modern architecture of the Arabian Gulf have used these elements according to its form and functional purposes. Yet there were others who concentrated in understanding its environmental and social character and utilize them in a modern way.

The University of Qatar represents functionally the clearest cases of the use of wind towers. The opening had 
been covered with perforated gypsum to allow for natural ventilation, Fig. 2 [3].

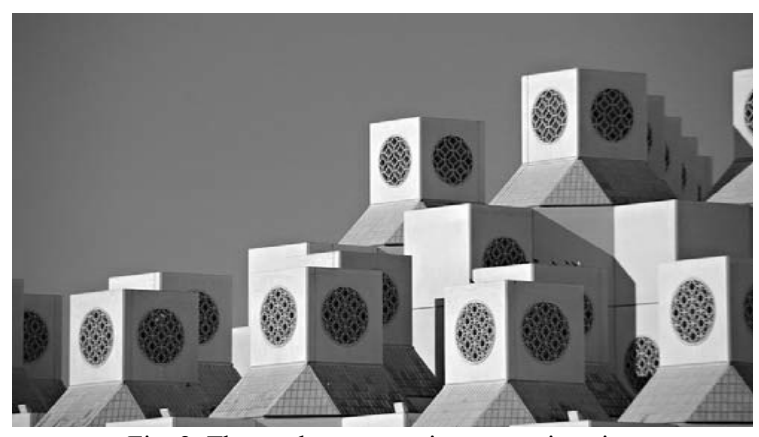

Fig. 2. The modern towers in qatar university.

Due to the negative environmental utilization of the new technology, many experimental studies to investigate the wind tower performance had been published. As a result, there were some buildings that utilize the air circulation inside their spaces with little or negligible use of mechanical means. Alhemedi, in his research, investigated the use of wind towers in hot dry regions in the cases of Alrahmaniah mosque and Alnezul Hotel in Aljof region [8]. The purpose of this implication is to save electrical energy consumption due to the use of mechanical air conditioning system. The hot air had been humidified as it penetrated through the tower device. Mazdar city in Abodhabi is another example of the use of wind towers under hot humid conditions. Rasem Badran used the wind tower in his design of the Islamic art museum, Qatar, which selected for in the Aga khan international prize, 1997 [9].

Many new technological devices had been explored to improve the cool air performance. Monodraught is one of the modern techniques that ensures light and ventilation performance in building interiors [10]. This device operates automatically to control the air movement with the group of temperature, wind level, and humidity sensors. This device can be found in various shapes. There were some buildings that had been designed in modern form through which the wind tower concepts translated such as Kensington Oval in Paradous; and Metropolis Zenith building by Foster.

The energy tower in Dubai, Designed by Gerber, one of the modern cases designed based on the theory of gain cool air through wind tower of 60 meter in diameter on top of the building simulating the traditional tower in modern form. Tassilo Hanger designed the wind tower building as another case representing the future architecture that uses wind catcher concept through the building envelope to grasp the air into the whole building skin. There were some recent experimental and theoretical studies that investigated the wind tower characteristics and its development such as the studies about Azad city [5]. Another study had been conducted as a master thesis [11]. These studies tried to explore and develop the environmental characteristics of the tower.

Though of all these recent design and research trials of improving the image and the environmental characteristics of the wind towers, there are many recent buildings emerged in various gulf cities such as Dubai, Abu Dhabi, Dammam, and AL Manama in which the wind towers appears with no environmental impact. It only had been represented as aesthetic symbol to draw the society's attention so that these images do not disappear from their minds. Some of them had been used as part of the stair cases, and as an esthetic memorial in the public gardens and sea shores. It also had been found as part of the modern building as an architectural space in Fig. 3.

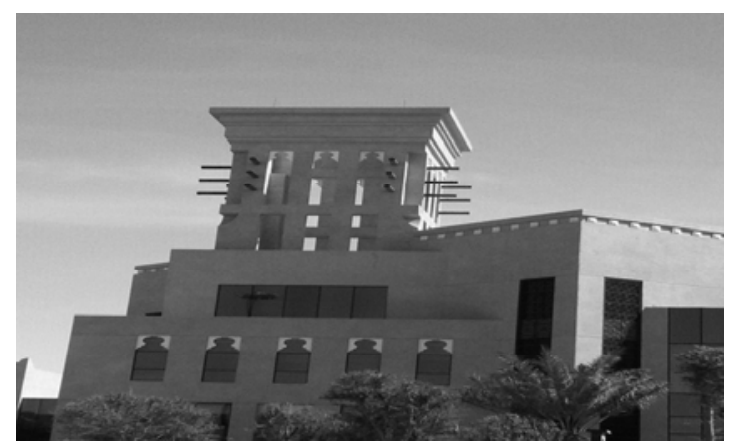

Fig. 3. The use of modern towers as a visual impression.

\section{The Purpose of Study}

Many studies investigated and analysed the development of the wind towers and its use as a natural ventilation device. These studies achieve success in zones with less humidity. Some others had been used with supplementary mechanical devices; which results in initial cost increase.

The attention of this paper is to investigate the environmental characteristics of the wind towers with special concern to the possibility of its use as a natural lighting device. To achieve this aim, the investigation will be through a field studies in one of the traditional local buildings using a light measurement meters. The investigation will explore the lighting characteristics through the use of this device. Moreover, another experimental process will investigate some of the modifications within the tower to improve its light performance. This paper will study the effect when the reflectivity of interior surfaces of the tower change.

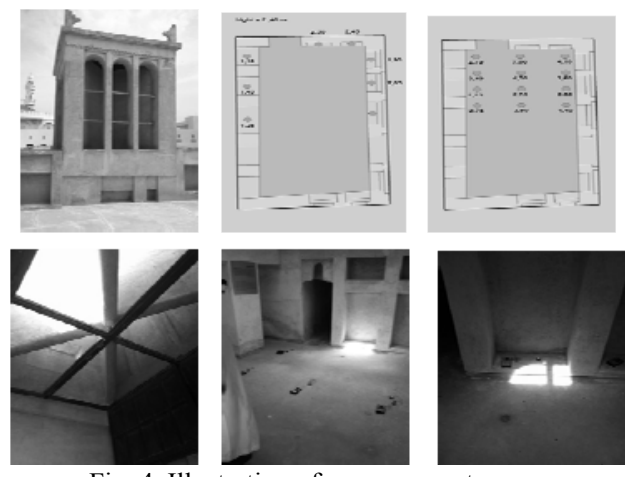

Fig. 4. Illustration of measurements process.

\section{A. The Natural Light Investigation}

The investigation had been applied to one of the wind towers in the house of Sheikh Isa ben Ali Al-Khalifa in Almehareq city of Bahrain. The concerned building had been visited, where the plan of the suggested space had been prepared. The position of twenty reading points on four rows had been marked on the floor of the space. The distance between each two point is $90 \mathrm{~cm}$ (see Fig. 4).

All reading results were documented, as shown in Fig. 5, with four portable light meters [12]. Two reading points had 
been added at $2.4 \mathrm{~m}$ in height on one of the sided shelves in the space. Moreover two other reading points were also measured. The first one is on the vertical surface at the top of the tower (4356 lux); while the other is on the vertical surface of the interior wall of the tower (1970 lux), (Fig. 5). The reflectance of the interior wall had been calculated as $45 \%$.

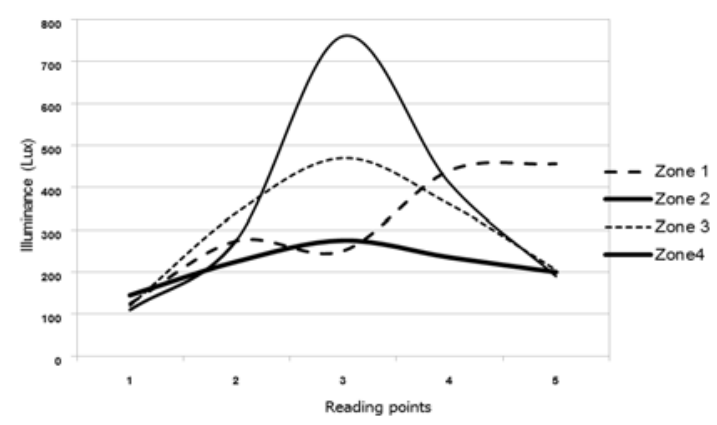

Fig. 5. The graphic illustration of the result.

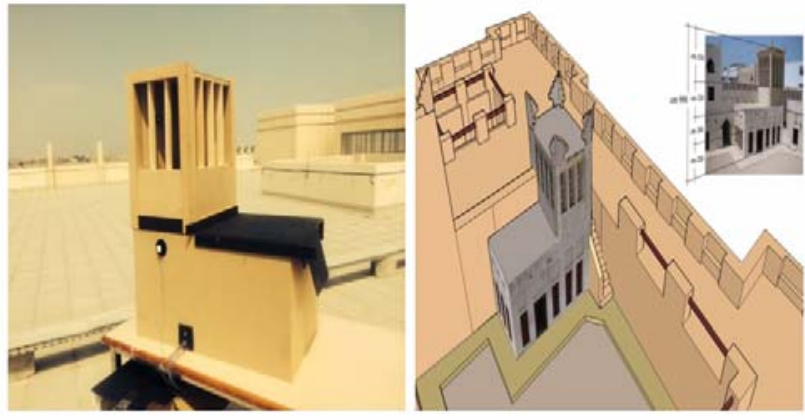

Fig. 6. The experiments procedures.

\section{B. 6.2 Analysis and Results}

The result had been presented with the use of a graphic program (Excel). The results concluded the following points:

1) The light level reduced at the vertical surface on the higher part of the tower as related to the light level outside the tower by $45 \%$. This means that the architectural components composing the upper part of the tower contribute in the reduction of the percentage of outdoor light level. In addition, it helps to reduce glare problem due to the penetration of direct sunlight. This also indicates the efficiency of the tower in the reduction of the accompanied temperature. This investigation illustrate that the light level at the upper portion of the tower (1970 lux) is higher than the international standards (500 lux) [13].

2) The results indicated that the light level at the lower portion of the tower extremely reduced at the height of $2.4 \mathrm{~m}$ by $88 \%$, as light level measured (250- $456 \mathrm{lux})$ which is about $12 \%$. This is much lower than the standards. It is important to clarify that these readings had been recorded while the side opening at the lower portion of the tower were closed to ensure that the light only come through the tower.

\section{THE IMPROVED INVESTIGATIONS}

The researcher investigated the improvement of the light performance inside the tower using three different reflective patterns. The first pattern is to paint the inner surface of the internal cross section of the tower of white paint. The reflectivity of the paint is $53 \%$. The other trial is to install grey sheets on the inner surface of the cross section where the reflectance is $42 \%$. The other trail is to use light original material which is the wooden sheets of a reflectivity of $21 \%$ to simulate the natural color of the mud. The model prepared for these experiments had been placed on the roof of the building (see Fig. 6).

The measurements had been taken as and average for each hour for the full day for each type of cross panel, as shown in Fig. 7. Six points had been recorded at the floor level of the tower; one point is at the top of the tower, and one point at the external vertical surface of the tower. The Megatron light meter with data logger had been used for these measurements.
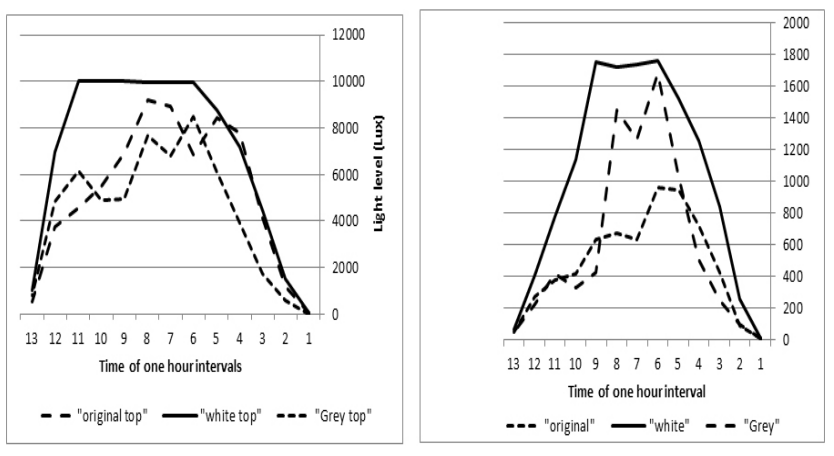

Fig. 7. The results of light performance inside the tower.

The results indicated the following points:

1) Both at the top and the bottom part of the tower, the light level indicated as above standard level.

2) The white cross panels provided light level about $75 \%$ of the day, while the wooden color panels could maintain about $50 \%$. However, the silvered color provides the least percentage as it only provides efficient light level at about $42 \%$ of the day. However, the percentage of light provided by the wooden color panels is the lowest but higher than the standard level of the original case measured on the real site.

\section{CONCLUSION}

The analysis of the field study indicated that the light level at the lower portion of the tower was generally lower than the standards (500 lux). Although the visibility level was at acceptable for the users, this will result in eye stress. The reduction in light level at the lower portion of the tower was due to few factors such as:

1) The height of the tower affects the contribution light performance at the lower part.

2) The inner walls of the tower contribute in light performance at the bottom of the tower. Moreover, this component greatly helps in the avoidance of direct sunlight and reduces the direct sun rays that cause high temperature.

\section{A. Recommendations}

Through the future experiments that could be investigated in the development of the visual characteristics of the wind 
tower, light could be ensured at its lower portion by different methods such as:

1) Install light sensors to catch sun light and reflect it downward.

2) Fix mirrors and lenses on the inner surfaces of the tower to contribute in transfer of light to the lower portion of the tower.

3) Investigate the light contribution of the side windows at the lower portion of the tower, especially as these windows originally represent an essential component in the enhancement of the natural ventilation system.

\section{REFERENCES}

[1] S. Kay, Architectural Heritage of the Gulf, Phillip Morris, 1991.

[2] S. M. Hassen The Effect of Malgaf Design as Natural Characters in Modern Housing, Asyout Engineering, 1999

[3] A. El-Shorbagy, "Design with nature: wind catcher as a paradigm of natural ventilation device in buildings," International Journal of Civil \& Environmental Engineering IJCEE-UENS, vol. 10, no. 3.

[4] S. John, Al-Muharraq, Architectural Heritage of a Bahraini City, 2006.

[5] M. Mahnaz, Analysis on Iranian Wind Catcher and Its Effect on Natural Ventilation as a Solution towards Sustainable Architecture, (Case Study: Yazd), 2009.

[6] Mohsen, "New method in modern architecture by employing natural element with helping technology," in Proc. the Iranian Students Scientific Conference, Malaysia, vol. 3, 2011

[7] A. Azami, "Badgir in traditional Iranian architecture," in Proc. International Conference Passive and Low Energy Cooling for the Built Environment, Greece, 2005.
[8] M. Alhemedi, "Strategies towards energy consumption in mosques," King Saud Magazine, pp.7-17, 1433.

[9] S. James, "The architecture of rasem badran," Thames \& Hudson, pp. 123, 2005.

[10] Monodraught, Wind Catcher, Natural Ventilation Systems, Buckinghamshire: Monodraught Ltd, 2006.

[11] N. Khatami, The Wind-Catcher, a Traditional Solution for Modern Problem, MPhil, University of Glamorgan, 2009.

[12] Megatron. [Online]. Available: http://www.Megatron.co.uk.

[13] CIBSE, "Code for interior LIGHTING," London Chartered Institution of Building Services Engineers, 1994.

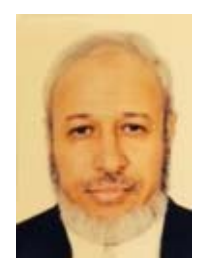

Egal K. Aljofi was born in Tabuk City, Saudi Arabia, in1959.

He received his bachelor degree in architecture and planning from King Faisal University, Dammam, Saudi Arabia in 1983. His master degree in architecture /energy from the University of Colorado, Denver, USA in 1987.

$\mathrm{He}$ gained his $\mathrm{PhD}$ in architecture with the special topics in day lighting design from the University of Cardiff, Wales, U. K, in 1995.

He started his carrier as a teaching assistant at King Faisal university in 1983 and became assistant professor at the same university in 1995 . He is now teaching the senior students as an associate professor at the University of Dammam. He participated in professional and academic organizations as a project juror and consultant. In addition he participated as a member of Jury committees for the master defenses at The Kingdom University in Bahrain.

His current research interests include the architectural education and the lighting performance of traditional architectural features.

Dr. Egal Aljofi is a member of Saudi Engineering Council in 2011, Member, CIBSE, and a member, Saudi Al-Omran Society since 1989. 